\title{
Chapter 1 \\ Photoacoustic Tomography: Deep Tissue Imaging by Ultrasonically Beating Optical Diffusion
}

\author{
Lihong V. Wang
}

\section{PHOTOACOUSTIC TOMOGRAPHY: \\ Deep Tissue Imaging by Ultrasonically Beating Optical Diffusion}

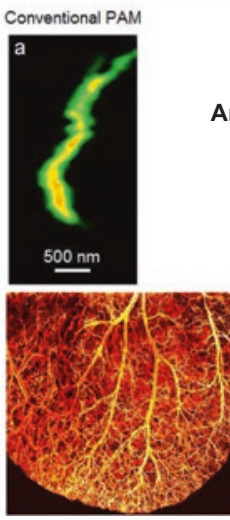

\author{
Lihong V. Wang, Ph.D., Bren Professor \\ Caltech Optical Imaging Laboratory (COIL)
}

Andrew and Peggy Cherng Department of Medical Engineering

Department of Electrical Engineering

California Institute of Technology
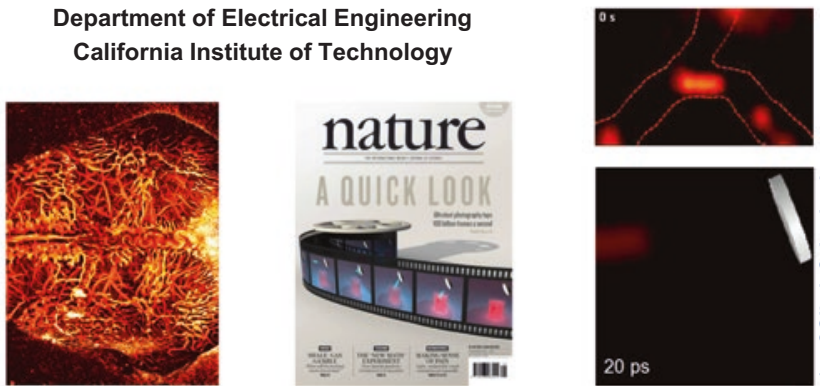

Photoacoustic tomography has been developed for in vivo functional, metabolic, molecular, and histologic imaging by physically combining optical and ultrasonic waves. Broad applications include early-cancer detection and brain imaging. Highresolution optical imaging - such as confocal microscopy, two-photon microscopy, and optical coherence tomography-is limited to superficial imaging within the optical diffusion limit ( $\sim \mathrm{mm}$ in the skin) of the surface of scattering tissue. By synergistically combining light and sound, photoacoustic tomography provides deep penetration at high ultrasonic resolution and high optical contrast.

Electronic Supplementary Material The online version of this chapter (https://doi. org/10.1007/978-981-13-7908-6_1) contains supplementary material, which is available to authorized users.

\footnotetext{
L. V. Wang $(\bowtie)$

California Institute of Technology, Pasadena, CA, USA

e-mail: LVW@Caltech.edu; http://COILab.Caltech.edu
} 
In photoacoustic computed tomography, a pulsed broad laser beam illuminates the biological tissue to generate a small but rapid temperature rise, which leads to emission of ultrasonic waves due to thermoelastic expansion. The unscattered pulsed ultrasonic waves are then detected by ultrasonic transducers. High-resolution tomographic images of optical contrast are then formed through image reconstruction. Endogenous optical contrast can be used to quantify the concentration of total hemoglobin, the oxygen saturation of hemoglobin, and the concentration of melanin. Exogenous optical contrast can be used to provide molecular imaging and reporter gene imaging as well as glucose-uptake imaging.

\section{Motivations for Imaging with Light}

\section{- Light-matter interaction uniquely positioned at the molecular level}

- Fundamental role of molecules in biology and medicine

- In vivo functional imaging analogous to functional MRI

- In vivo metabolic imaging analogous to PET

- In vivo molecular imaging of gene expressions or disease markers

- In vivo label-free histologic imaging of cancer without excision

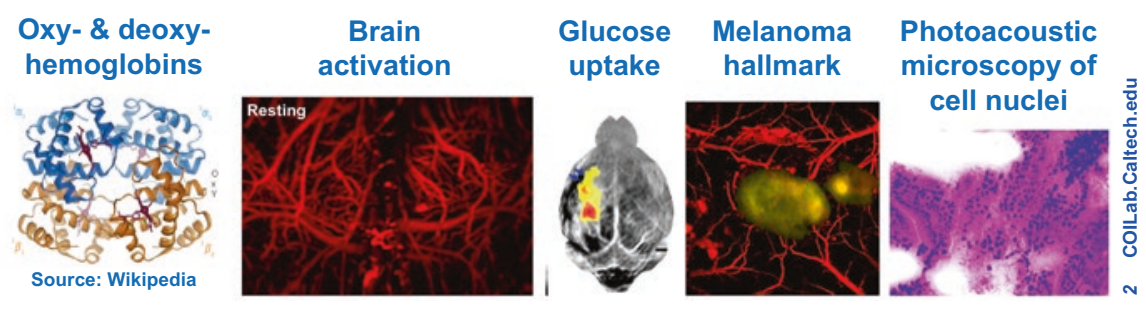

Challenges in Optical Penetration
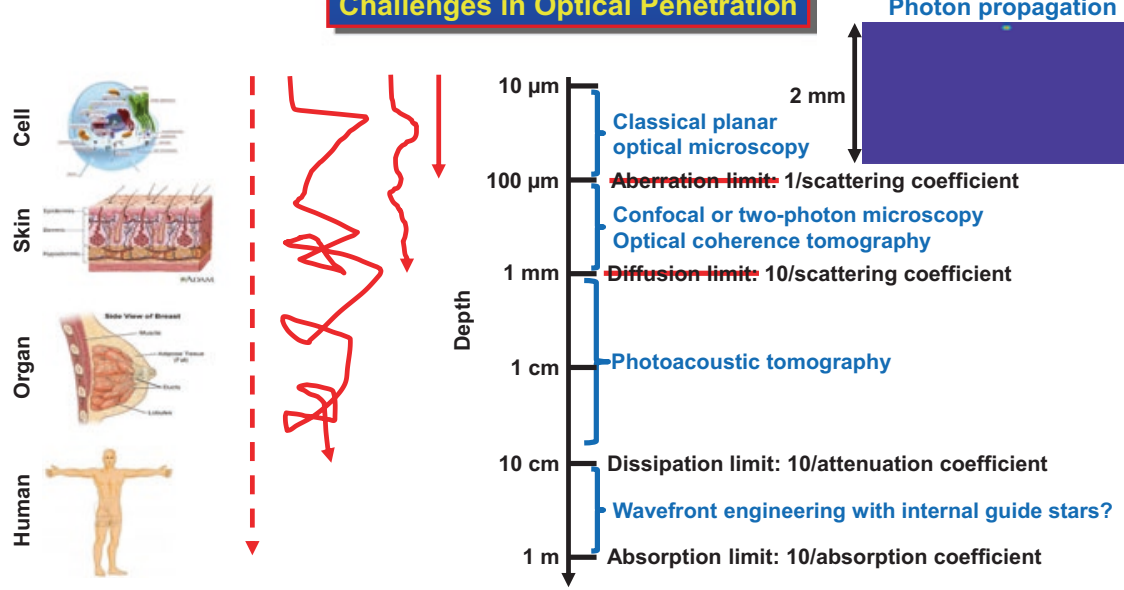

LV Wang, HI Wu, Biomedical Optics (Wiley, 2007); LV Wang, JJ Yao, Nature Methods 13, 627, 2016 

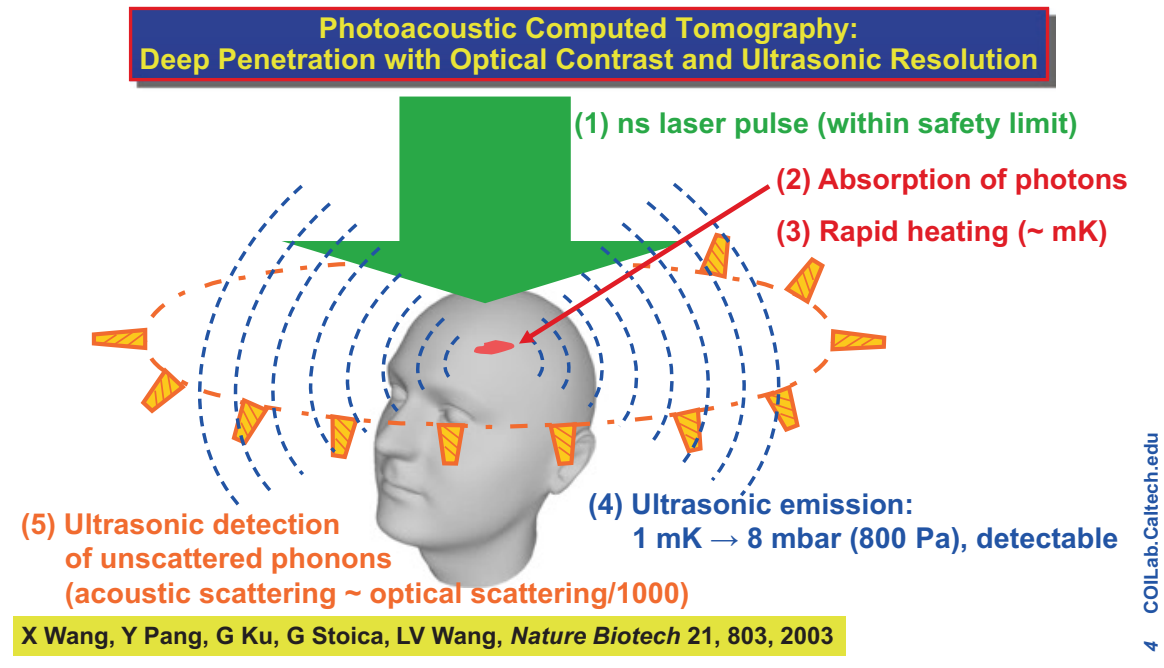

In photoacoustic microscopy, a pulsed laser beam is delivered into the biological tissue to generate ultrasonic waves, which are then detected with a focused ultrasonic transducer to form a depth resolved 1D image. Raster scanning yields 3D high-resolution tomographic images. Super-depths beyond the optical diffusion limit have been reached with high spatial resolution. The following image of a mouse brain was acquired in vivo with intact skull using optical-resolution photoacoustic microscopy.

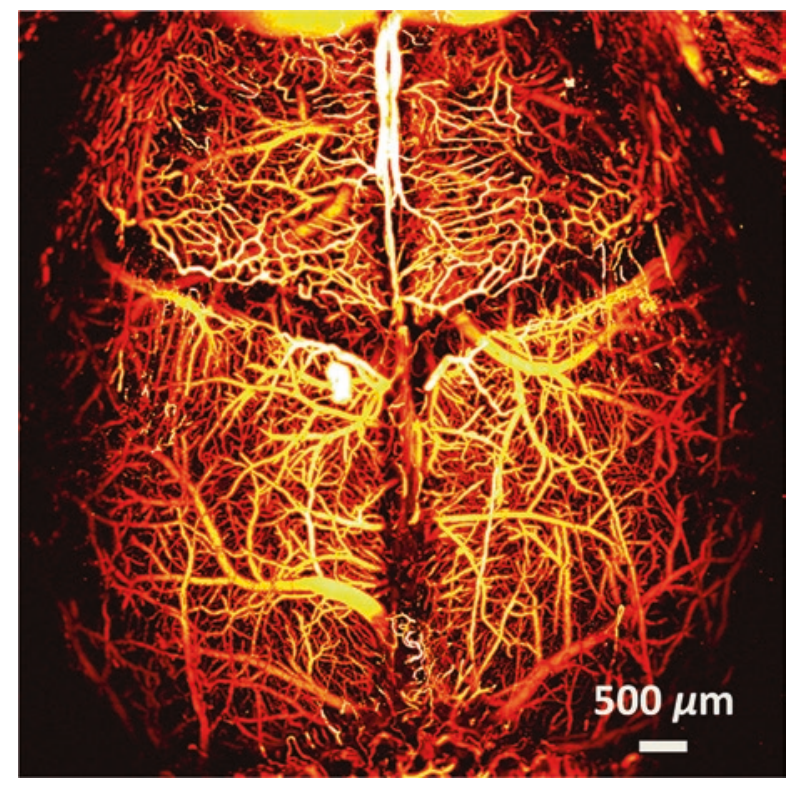


First Functional (Also First In Vivo) Photoacoustic Tomography in Small Animals with Intact Scalp and Skull

\section{Left-whisker stimulation}

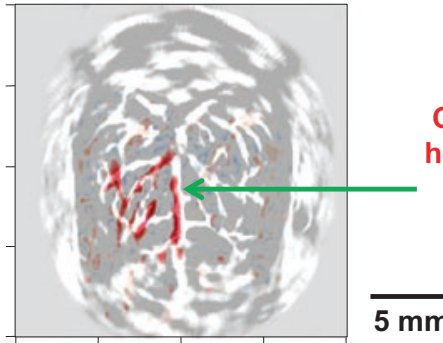

\section{Right-whisker stimulation}

Min

Differential absorption

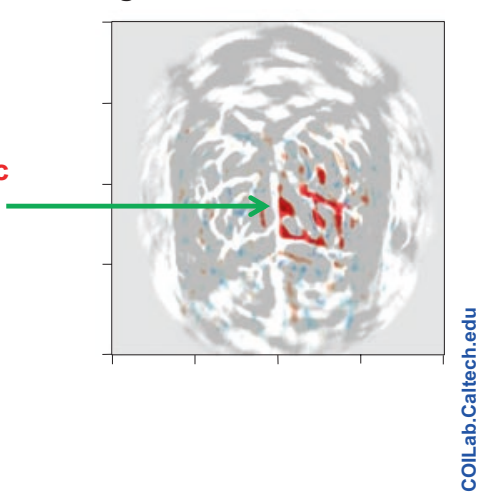

X Wang, Y Pang, G Ku, G Stoica, LV Wang, Nature Biotech 21, 803, 2003

The annual conference on photoacoustic tomography has become the largest in SPIE's 20,000-attendee Photonics West since 2010.

Wavefront engineering and compressed ultrafast photography will be touched upon.

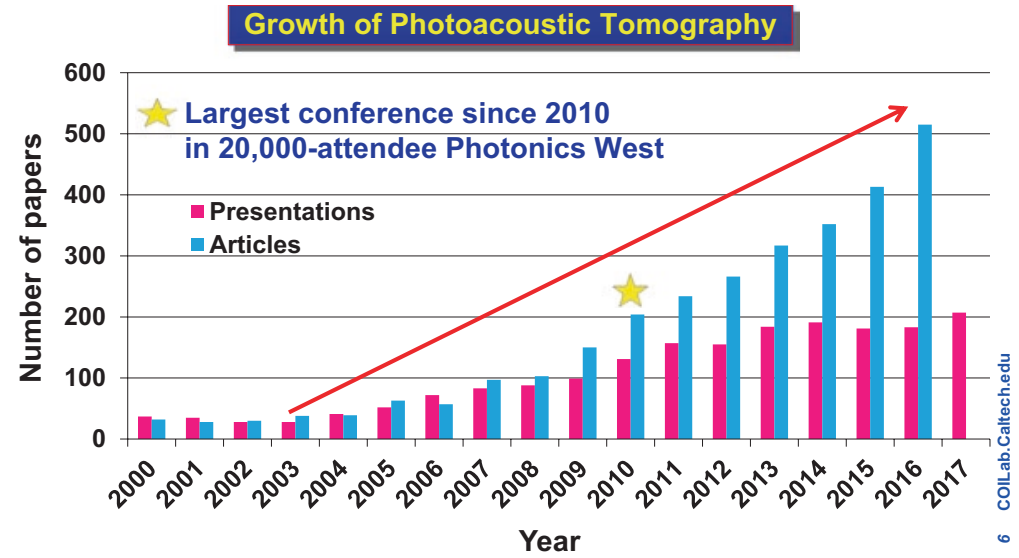


Omniscale In Vivo Photoacoustic (PA) Tomography with Consistent Contrast

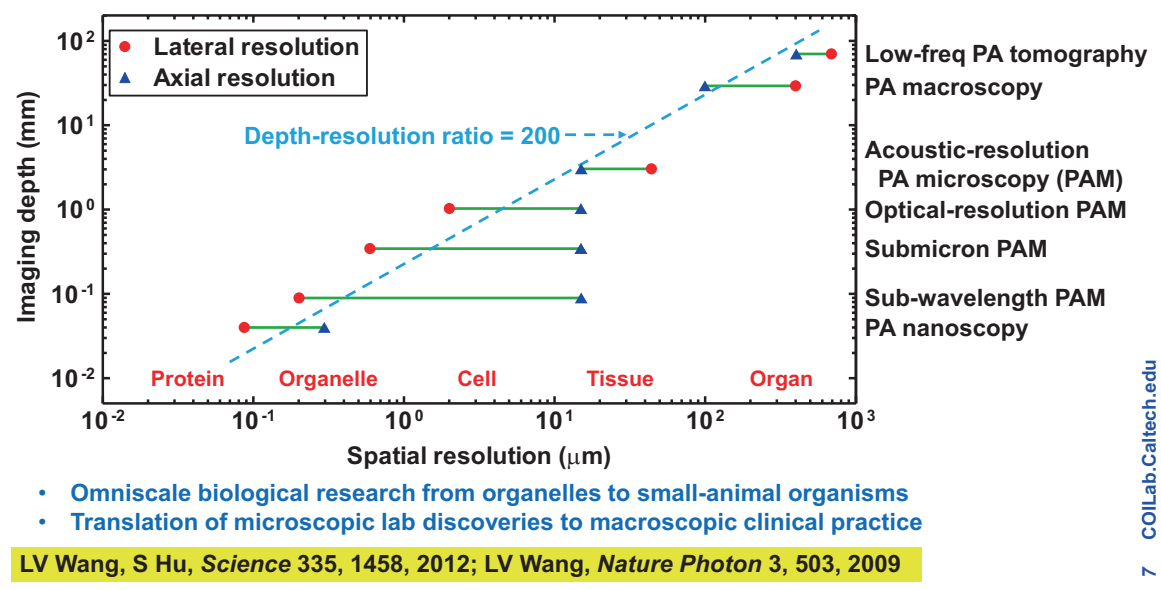

\section{Selected Publications:}

1. Nature Biotechnology 21, 803 (2003).

2. Nature Photonics 5, 154 (2011).

3. Science 335, 1458 (2012).

4. Nature Methods 13, 67 (2016).

Open Access This chapter is licensed under the terms of the Creative Commons Attribution 4.0 International License (http://creativecommons.org/licenses/by/4.0/), which permits use, sharing, adaptation, distribution and reproduction in any medium or format, as long as you give appropriate credit to the original author(s) and the source, provide a link to the Creative Commons licence and indicate if changes were made.

The images or other third party material in this chapter are included in the chapter's Creative Commons licence, unless indicated otherwise in a credit line to the material. If material is not included in the chapter's Creative Commons licence and your intended use is not permitted by statutory regulation or exceeds the permitted use, you will need to obtain permission directly from the copyright holder.

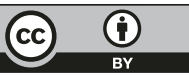

